\title{
FRANCISCO LAPORTA Y LIBORIO HIERRO EN SU JUBILACIÓN (A MODO DE PRESENTACIÓN)
}

\author{
Alfonso Ruiz Miguel \\ Universidad Autónoma de Madrid
}

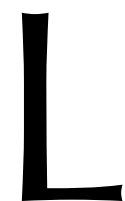

iborio HIERRO y Francisco LAPORTA se jubilaron el curso pasado. Con ese motivo, en el Área de Filosofía del Derecho de la Autónoma de Madrid pensamos que la mejor manera de mostrar nuestra especial consideración hacia ellos era organizar una Jornada de debate sobre sus escritos ${ }^{1}$. El formato de la Jornada no había de ser novedoso, pues se había ya probado con éxito en el homenaje por el 80..$^{\circ}$ cumpleaños de Ernesto GARZÓN VALDÉS, celebrado en junio de 2007 en Alicante y publicado en el núm. 30 de Doxa. Se trataría de propiciar la exposición por cada participante de un breve comentario sobre algún punto más bien específico de los escritos de Paco o de Curro (que así es como le llamamos los amigos desde siempre) que permitiera un debate sobre su obra.

La pretensión de concentrar el homenaje en un solo día, debida sobre todo a limitaciones de financiación, nos inclinó desde el principio a una cierta restricción en la convocatoria de invitados mediante dos criterios que consideramos, además de sensatos, fáciles de explicar y de aplicar con coherencia: que participaran colegas de universidades españolas y que hubieran tenido un significativo grado de proximidad con los dos protagonistas (un tercer criterio, mantenido para la Jornada pero no para esta publicación, fue que los compañeros de la Autónoma no intervendríamos salvo para resumir las ponencias de quienes no pudieran asistir y para participar en los dos debates generales previstos, que, sin embargo, y a pesar de la rigurosa contención de los ponentes a los tiempos marcados, no hubo tiempo de llevar a cabo).

La Jornada, que se celebró el 25 de noviembre de 2016, fue un éxito tanto desde el punto de vista interno a los filósofos del Derecho que participamos como del de los colegas de la Facultad que asistieron como observadores interesados. Junto a los estimulantes escritos de Liborio y Paco, el éxito de nuestra convocatoria se debe a los participantes y a la alta calidad de la filosofía del Derecho española representada, en directo o en diferido, aquel día y en esta publicación.

Las dos sesiones en que se dividió la Jornada - teoría del Derecho por un lado y filosofía política y derechos humanos por otro- son los dos grandes temas a los que

${ }^{1}$ Las tareas de organización, asumidas por Juan Carlos BAYÓN, José Luis COLOMER, Luis RodRíGuEZ ABASCAL y Borja BARRAGUÉ, merecen aquí especial mención y agradecimiento. 
LAPORTA y HiERRO han dedicado su vida académica. Pero, sin prescindir de esa distinción, tampoco hay que tomarla demasiado en serio, pues es mucho menos nítida de lo que sugiere la diferencia entre la política y el Derecho. No se trata solo de que los «derechos humanos» puedan, suelan y deban ser tratados desde la teoría del Derecho y de filosofía política, sino que una buena filosofía jurídica, en cuanto reflexión sobre la justicia, ha de mirar siempre al Derecho tanto desde sus rasgos y complejidades conceptuales como desde sus justificaciones éticas y políticas. Que esa ha sido la manera de entender la filosofía del Derecho por parte de nuestros dos autores está claro en la semblanza bio-bibliográfica que esbozo a continuación.

Tanto Paco como Liborio, que es apenas dos meses más joven, coincidieron en los mismos cursos de Derecho en la Universidad Complutense a mediados de los años sesenta. Y ambos comenzaron su carrera académica en 1968 en el Departamento de Filosofía del Derecho que allí encabezaba Joaquín RuIZ-GiMÉNEZ, desde 1963 comprometido promotor de la revista Cuadernos para el Diálogo. Don Joaquín, como en el mundo académico se le llamaba siempre, ya tenía como «adjuntos» a Elías Díaz y a Gregorio PeCES-BARBA. Fue con Elías con quien nuestros dos homenajeados decidieron hacer sus tesis, la primera más jurídica y la otra más histórico-política, pero ambas con un propósito idéntico de renovación de la filosofía jurídica en la España de la época.

La tesis de Paco, sobre el jurista y sociólogo ovetense Adolfo POSADA (1974), se inscribía en la línea propiciada y cultivada por el mismo Elías de «recuperación» del mejor pensamiento contemporáneo español, brotado entre finales del siglo XIX y principios del Xx alrededor del regeneracionismo krausista y la Institución Libre de Enseñanza y fructificado también en autores defensores de un socialismo liberal o democrático: las tesis de Emilio LAMO DE ESPINOSA y de Virgilio ZAPATERO sobre Julián BESTEIRO y Fernando DE LOS Ríos, como el libro del propio Elías sobre el krausismo español, que se publicaron entre 1973 y 1974, dan testimonio de todo ello. En el caso de LAPORTA, junto al libro sobre POSADA, la relación con la ILE se iría estrechando con los años, institucional y académicamente, entre otros con nuevos estudios sobre GINER DE LOS RíOs (1977) y una extensa investigación sobre la Junta para Ampliación de Estudios, en la que colaboramos también Virgilio ZAPATERO, Javier SOLANA y yo mismo, y de la que se publicó solo una síntesis parcial (1987a). Todo ello señala una clara influencia del liberalismo institucionista, especialmente en su visión de la educación, que, como causa y como efecto, me parece decisiva en el desarrollo intelectual y personal de Paco.

La tesis de Curro, en cambio, se orientó hacia el realismo jurídico escandinavo (1981) y vino a desarrollar la revisión crítica que el mismo Elías DíAz había comenzado a proponer frente a la mixtura de iusnaturalismo católico declamatorio y positivismo formalista efectivo que tendía a caracterizar la enseñanza del Derecho en el franquismo. Elías, especialmente en su curso Sociología y Filosofía del Derecho (1971, 2. ${ }^{a}$ ed. de 1980) había dirigido la atención a la línea de KELSEN, HART, BOBBIO y, aunque no tan centralmente, Ross como la visión positivista crítica más prometedora para una renovación de la teoría jurídica. La tesis de Liborio, como la mía sobre BoBBiO de poco tiempo después, se inscriben en ese marco, que es, dicho en síntesis, el del positivismo hartiano, en el que también se ha situado Paco. Aunque DwORKIN ya había publicado sus principales textos de crítica al positivismo de HART, entonces estábamos todavía 
algo lejos de la polémica sobre el constitucionalismo y el positivismo incluyente o excluyente que arreciaría ya entrado el presente siglo.

De momento, con la llegada de los socialistas al gobierno, dentro de las décadas de los ochenta y los noventa hay un cierto hueco en la bibliografía de nuestros dos homenajeados. En el caso de Liborio, debido a su participación política en los gobiernos de Felipe González como subsecretario del Ministerio de Justicia entre 1982 y 1990, actividad extraacadémica que amplió dos años más como presidente del Tribunal de Defensa de la Competencia; luego, entre 1993 y 2014, fue vocal y presidente del Comité Español de Disciplina Deportiva, pero ahora compatibilizando esa tarea tan poco filosófica, aunque sí jurídica, con su vuelta a la Universidad en 1992, donde tras obtener la cátedra desempeñó un decanato de cuatro años (el máximo de facto en nuestra Facultad por una costumbre intacta hasta hoy) que ha dejado una inmejorable memoria. En el caso de LAPORTA, su incursión, o excursión, a los aledaños de la política, más breve y más relacionada con la academia, le llevó a la dirección del entonces llamado Centro de Estudios Constitucionales de 1987 a 1993, donde ha quedado una apreciable huella de su paso tanto en el área de las publicaciones como en la de los estudios de posgrado.

Tras las tesis doctorales, lo más llamativo del currículum académico de Curro y Paco es la gran similitud de sus temas y enfoques. Los dos grandes temas sobre los que se desenvuelven sus publicaciones giran en torno a los derechos humanos y sus valores justificativos y al Estado de Derecho y el imperio de la ley, que por lo demás tienen evidentes conexiones entre sí (las naturales e inevitables desviaciones de los anteriores temas no son numerosas, pudiendo citarse HIERRO, 1989, 1997, 2003 a y 2011b; y LAPORTA, 1987a 1997b 2003b).

El tema de los derechos humanos atraviesa el recorrido de uno y otro. En la bibliografía de Paco, deben registrarse aquí sus artículos sobre los principios de libertad (1983) y de igualdad (1985 y 1994) y los dedicados al concepto de derechos humanos (1987b) y, en desarrollo de él, al problema de la protección jurídica de los derechos sociales (2004a). Todos ellos han sido y siguen siendo profusamente citados en la abundante literatura en lengua española que ha seguido discurriendo sobre tales cuestiones. Aparte del método claro y analítico y de su cercanía política con el pensamiento socialdemócrata, quizá pueda destacarse en todos ellos su inclinación a no sortear las dificultades conceptuales y prácticas de intentar combinar los ideales en una totalidad acabada y sin fisuras: puede ejemplificarlo bien la idea, tan deliberadamente provocativa como todavía hoy discutida, de la incompatibilidad entre las demandas de extensión en el elenco de los derechos y de profundización en su protección.

Por su parte, los escritos de Liborio sobre los derechos humanos han atendido con similar peso argumentativo tanto a los aspectos conceptuales o teórico-jurídicos —así ocurre en el estudio dedicado a las modalidades deónticas de derecho y deber (2000), pero también en sus análisis más amplios sobre el concepto de justicia (2002a y 2002b) - como a la perspectiva más filosófica de su justificación ético-política. Ambas líneas están presentes en varios de los anteriores estudios pero tienen un especial protagonismo en el artículo en discusión sobre los derechos sociales en AlEXY (2007), en el dedicado al problema de los titulares de los derechos humanos (2013) y, sobre todo, en los que tratan sobre la autonomía individual como fundamento de esos derechos 
(2014a) y sobre el reto pendiente de su extensión a nivel global (2014b). Ambas perspectivas, por lo demás, se encuentran bien ensambladas en su recién publicado libro sobre los derechos humanos (2016), que hace una recuperación sistematizada, ampliada y revisada de muchos de los textos anteriores. Se trata de una obra que, más allá de su propósito didáctico, cubre un nicho algo abandonado y ya necesitado de renovación después de los cursos sobre derechos fundamentales de Gregorio PECES-BARBA, que fueron los pioneros en España.

El tema del Estado de Derecho y el imperio de la ley se puede distinguir del anterior, aun solo relativamente, por proponer de manera más directa la ardua cuestión de las relaciones entre Derecho, poder y moral y, por tanto, por apelar al cabo de las tormentas de las actuales discusiones a propósito del (neo)constitucionalismo, con sus dos derivaciones distintas pero igualmente debatidas e importantes: la crisis del positivismo jurídico y la concepción de la democracia que subyace a los controles de constitucionalidad. De todos esos temas hay abundante testimonio en las publicaciones de nuestros dos autores, desde el libro recopilatorio de Liborio, Estado de Derecho. Problemas actuales (2001) hasta la obra de mayor impulso e impacto de Paco, El imperio de la ley. Una visión actual (2007a), pasando por diversos artículos de uno y otro sobre la democracia constitucional (HIERRO, 1994, 2011a; y LAPORTA, 1989, 2000, 2001, 2003a), por los importantes estudios de Liborio sobre el positivismo jurídico, la crisis de la ley o el realismo jurídico genovés (2002c, 2003b y 2014c) y, en fin, por los dos polémicos textos de Paco a propósito del nacionalismo y de los derechos históricos en nuestra Constitución (1990 y 2007b).

El paralelismo en las vidas y en las obras de Paco y Liborio se confirma en sus profundas coincidencias de fondo, teóricas e ideológicas. Es cierto que el imperio de la ley, para Paco identificable con los ocho rasgos del Derecho según Lon FULLER, propone un concepto deliberadamente más restringido que el de Estado de Derecho en la visión de Liborio, tributaria de la liminar advertencia de Elías DíAZ de que «no todo Estado es Estado de Derecho». Sin embargo, esa diferencia entre nuestros dos autores se desvanece en cuanto se cae en la cuenta de que en la concepción general de LAPORTA sobre la justicia el imperio de la ley es una condición necesaria pero no suficiente, que debe ser completada con las exigencias de la legitimidad popular del poder legislativo y la garantía de los demás derechos básicos. No es extraño que, compartiendo también una común fundamentación ética última esencialmente monista en el valor de la autonomía individual, ambos terminen confluyendo en la defensa de la democracia liberal.

Tampoco hay diferencias sustanciales sobre el positivismo jurídico, en el que no solo ellos sino el conjunto del Área de Filosofía del Derecho de la Autónoma de Madrid pasamos por ser el último fortín de esa corriente en el país, de manera similar a como al Área de Alicante se le tiene por la punta de lanza del postpositivismo hispánico o a los genoveses, del realismo jurídico contemporáneo. Ferlosio, sin duda con literaria y atrabiliaria voluntad de exageración, sentenció en una ocasión que «nunca se convence a nadie de nada». Creo que la experiencia de nuestro Área permite desmentir tamaña universalización temporal, personal y material. Si, más allá de nuestros ineludibles versos libres, hubiéramos en efecto llegado a coincidir en muchos aspectos sustantivos, habría sido desde nuestras divergencias de partida y por una especie de ósmosis común generada sobre todo en tantas conversaciones y discusiones, siempre in 
re y nunca ad hominem, muchas de ellas a la bendita hora del café; al igual que también se ha podido producir en algún momento el fenómeno inverso de la revisión y apartamiento de algunas de esas coincidencias osmóticas por parte de algunos de nosotros: como tengo muy cerca un ejemplo de esas idas y venidas, lo que yo mismo mantengo ahora del positivismo jurídico es apenas el positivismo interpretativo, que considero fundamentable dentro de la concepción dworkiniana de la mejor interpretación posible del material jurídico.

Pero si las coincidencias entre Curro y Paco son intensas y extensas en temas y en fundamentación, creo que mantienen diferencias significativas en el método. En la conocida división de Arquíloco-Berlin, mientras Curro es un claro caso de erizo que, aun con grandes cualidades analíticas, busca la síntesis en un principio unificador, Paco me parece un igualmente claro caso de zorra que, aun partiendo de una voluntad unificadora, ama más bien entretenerse en los complejos vericuetos del análisis. Y de las respectivas virtudes de una y otra actitud surgen a veces los correspondientes defectos, que me voy a permitir ejemplificar en dos puntos concretos para ir cerrando esta doble laudatio con un mínimo apunte crítico.

Los dos puntos atañen al mismo problema teórico: el concepto de democracia. En Paco es proverbial la defensa de la democracia representativa frente a la democracia directa, en la que ve los mil problemas que un buen zorro sabe detectar cuando busca bien, hasta el punto de hacer dudar de si lo malo de la democracia no será el propio pueblo y, por tanto, de correr el riesgo (como comentaba Luis RODRíGUEZ ABASCAL a propósito de LAPORTA, 2016, en uno de nuestros cafés) de tirar el agua sucia con el niño. Mi crítica interna a esa posición es que su desconfianza hacia la participación popular no termina de casar bien con el valor privilegiado que atribuye a la autonomía individual como fundamento último tanto del imperio de la ley como de la legitimidad del sistema político.

Por su parte, Liborio defiende la democracia enmendando la que considera confusa disociación berliniana entre la libertad negativa y la positiva para afirmar, como buen erizo, no solo que ambas son manifestaciones de la misma autonomía individual según se ejerza en el ámbito estrictamente personal o en condiciones de interdependencia, sino también que una y otra pueden ser acordadas entre sí conforme al «principio de conservación de la libertad general», según el cual «no ha de someterse al escenario de la libertad positiva ningún ámbito de la acción de una persona que no requiera decisiones interdependientes» (2002b: 44; y 2016: 164). Sin objetar nada a este criterio sustantivo, no tengo claro el alcance que para HIERRO debe tener el criterio procedimental que también es imprescindible para resolver las metadecisiones a propósito de qué decisiones son o no interdependientes, que es el espacio de conflicto natural entre las dos formas de libertad en cuestión. En un modelo de democracia deliberativa y de constitucionalismo débil como el defendido por Liborio (2016: 109-203), parece que el procedimiento legítimo en último término para adoptar dichas metadecisiones es la decisión colectiva por mayoría, pero ese procedimiento puede poner en riesgo la libertad negativa. Cabe formular el problema recordando a ROUSSEAU: «Es cosa convenida que aquello que en virtud del pacto social enajena cada uno de su poder, de sus bienes y de su libertad es solo la parte de todo ello cuyo uso importa a la comunidad, pero es preciso convenir también que solo el soberano puede juzgar esa importancia» (Del 
contrato social, II.iv; cursiva mía). El «pero» de la frase de ROUSSEAU deja claro que la decisión del soberano (esto es, el criterio procedimental) es el criterio de legitimidad que domina sobre el criterio sustantivo de los derechos, dejando abierto el riesgo de que la mayoría nos obligue a ser libres. ¿Ocurre lo mismo en la concepción de Liborio?

Termino ya como terminé en la presentación de la Jornada de noviembre pasado, recordando que en una ocasión similar, en su conferencia de despedida en la Autónoma, Francisco MURILlo FERROL, con la falta de complacencia que es de fama en los granadinos, comenzó diciendo: «Jubilarse viene de júbilo, pero el júbilo no es del que se va, es de los que se quedan». En el caso de Paco y Curro no podemos decir lo mismo, porque siguen siendo profesores eméritos y la Facultad les ha asignado un despacho que comparten con Elías en el que esperamos seguir viéndoles a los tres por mucho tiempo.

\section{BIBLIOGRAFÍAS SELECCIONADAS ${ }^{2}$}

\section{Liborio L. Hierro Sánchez-Pescador}

1981: El realismo jurídico escandinavo. Una teoría empirista del derecho, Valencia: Fernando Torres; 2. ${ }^{a}$ ed., revisada y abreviada, Madrid: Iustel, 2009.

1989: «Libertad y responsabilidad penal», Anuario de Derecho Penal y Ciencias Penales, núm. XLII.

1994: «Ross y Bobbio sobre la Democracia. El racionalismo de dos emotivistas», en Á. LLAMAS (ed.), La figura y el pensamiento de Norberto Bobbio, Madrid: Universidad Carlos III-BOE. 1997: «Las profesiones jurídicas. Una visión de conjunto», Sistema, núm. 137.

1998: Estado de derecho. Problemas actuales, México: Fontamara; 2. ${ }^{a}$ ed., 2001.

2000: «Conceptos jurídicos fundamentales. (I) De las modalidades deónticas a los conceptos de derecho y deber», Revista Jurídica. Universidad Autónoma de Madrid, núm. 3.

2002a: Justicia, igualdad y eficiencia, Madrid: Centro de Estudios Políticos y Constitucionales. 2002b: «El concepto de justicia y la teoría de los derechos», en E. DíAz y J. L. COLOMER (eds.),

Estado, justicia, derechos, Madrid: Alianza.

2002c: «¿Por qué ser positivista?», Doxa, núm. 25.

2003a: La eficacia de las normas jurídicas, Barcelona: Ariel; 2. ${ }^{a}$ ed., México: Fontamara, 2010. 2003b: «Igualdad, generalidad, razonabilidad y crisis de la ley», Doxa, núm. 26.

2007: «Los derechos económico-sociales y el principio de igualdad en la teoría de los derechos

de Robert Alexy», en R. GARCÍA MANRIQUE (ed.), Robert Alexy. Derechos sociales y ponderación, Madrid: Fundación Coloquio Jurídico Europeo (también en Doxa, núm. 30).

2010: «Deontología de las profesiones jurídicas. Una discusión académica», Teoría y Derecho.

Revista de pensamiento jurídico, núm. 8 [también en C. GARCía PASCUAL (ed.), El buen juris-

ta. Deontología del Derecho, Valencia: Tirant lo Blanch, 2013].

2011a: «Derechos, democracia y justicia constitucional», Jurisdicción constitucional y democracia, Actas de las XVI Jornadas de la Asociación de Letrados del Tribunal Constitucional, Madrid: Centro de Estudios Políticos y Constitucionales.

2 Esta selección bibliográfica fue realizada por cada uno de los dos autores como base para los comentarios de la Jornada de homenaje, pero me he permitido añadir algún título más al que hago referencia en mi presentación (nota de A. RuIZ MiguEL). 
2011b: «Sobre el modesto principio de que la ignorancia del derecho no excusa de su cumplimiento», en P. BRUNET y F. J. ARENA (eds.), Cuestiones contemporáneas de teoría analítica del derecho, Madrid: Marcial Pons.

2013: «¿Quién tiene derechos humanos?», Teoría y Derecho. Revista de pensamiento jurídico, núm. 14.

2014a: «Autonomía y derechos humanos. ¿Para qué se inventaron los derechos humanos?», en L. L. Hierro (ed.), Autonomía individual frente a autonomía colectiva. Derechos en conflicto, Madrid: Marcial Pons, 27-52.

2014b: «Justicia global y justicia legal. ¿Tenemos derecho a un mundo justo?», en A. RuIZ Miguel (ed.), Entre Estado y Cosmópolis, Derecho y Justicia en un mundo global, Madrid: Trotta.

2014c: «El realismo jurídico ¿ciencia o cultura?», Analisi e Diritto.

2016: Los derechos humanos. Una concepción de la justicia, Madrid: Marcial Pons.

\section{Francisco J. Laporta San Miguel}

1974: Adolfo Posada: Política y sociología en la crisis del liberalismo español, Madrid: Editorial Cuadernos para el Diálogo.

1977: Antología pedagógica de Francisco Giner de los Ríos, selección y estudio preliminar de F. LAPORTA, Madrid: Santillana.

1983: «Sobre el uso del término libertad en el lenguaje político», Sistema, núm. 52.

1985: «El principio de igualdad: introducción a su análisis», Sistema, núm. 67.

1987a (y Ruiz Miguel, A., Zapatero, V., y Solana, J.): «Los orígenes culturales de la Junta para Ampliación de Estudios», Arbor, núm. 493, CXXVI, enero 1987, 17-87; 2. ${ }^{a}$ parte, núms. 499-500, CXXVII, julio-agosto, 9-137.

1987b: «Sobre el concepto de derechos humanos», Doxa, núm. 4.

1989: «Sobre la teoría de la democracia y el concepto de representación política», Doxa, núm. 6. 1990: «La quimera del nacionalismo», en Claves de Razón Práctica, núm. 14.

1993: Entre el Derecho y la moral, México: Fontamara (varias reediciones).

1994: «Problemas de la igualdad», en A. VALCÁrCEL (ed.), El concepto de igualdad, Madrid:

Fundación Pablo Iglesias.

1996: «Poder y Derecho», en Enciclopedia Iberoamericana de Filosofía, vol. 11.

1997a: «Vindicación del Precedente Judicial en España», Anuario de la Facultad de Derecho de

la Universidad Autónoma de Madrid, núm. 1.

1997b: «El derecho a informar y sus enemigos», Claves de Razón Práctica, núm. 72; reeditado en

E. Bonete Perales (ed.), Madrid: Tecnos.

2000: «El cansancio de la democracia», Claves de Razón Práctica, núm. 99.

2001: «Los problemas de la democracia deliberativa», Claves de Razón Práctica, núm. 109.

2003a: «Filosofía del derecho y norma constitucional», en F. J. LAPORTA (ed.), Constitución: problemas filosóficos, Madrid: Centro de Estudios Políticos y Constitucionales.

2003b: «A modo de introducción: La naturaleza de las reflexiones sobre la enseñanza del derecho», en F. J. LAPORTA (ed.), La Enseñanza del Derecho, Anuario de la Facultad de Derecho de la Universidad Autónoma de Madrid, núm. 6.

2004a: «Los derechos sociales y su protección jurídica: introducción al problema», en J. BETEgÓn, F. J. Laporta, J. R. De PÁramo y L. PRieto SAnchís (eds.), Constitución y derechos fundamentales, Madrid: Centro de Estudios Políticos y Constitucionales. 
2004b: «Las dos vías para la reforma de la Constitución», Claves de Razón Práctica, núm. 145. 2007a: El Imperio de la ley. Una visión actual, Madrid: Trotta.

2007b (y SaIz Arnaiz, A.): Los derechos históricos en la Constitución, Madrid: Centro de Estudios Constitucionales.

2008: «Los vecinos de Kitty Genovese», en En el umbral del tercer milenio, Exposición Universal de Sevilla, 1992, también aparecido en Tiempo de Paz, núm. 88.

2010: «Algunas incógnitas del principio de autonomía personal en tratamientos médicos», en B. Mendoza Buergo (ed.), Autonomía personal y decisiones médicas. Cuestiones éticas y jurídicas, Madrid: Civitas-Thompson Reuters-UAM.

2016: «Contra el referéndum», El País, 31 de octubre. 